\title{
Transcapillary escape rate and albuminuria in Type II diabetes. Effects of short-term treatment with low-molecular weight heparin
}

\author{
S. Nielsen ${ }^{1}$, A. Schmitz ${ }^{1}$, T. Bacher ${ }^{2}$, M. Rehling ${ }^{2}$, J. Ingerslev ${ }^{3}$, C. E. Mogensen ${ }^{1}$ \\ ${ }^{1}$ Medical Department M (Endocrinology \& Diabetes), Århus Kommunehospital, Århus, Denmark \\ ${ }^{2}$ Department of Clinical Physiology and Nuclear Medicine, Århus Kommunehospital, Århus, Denmark \\ ${ }^{3}$ Department of Clinical Immunology, University Hospital, Skejby, Denmark
}

\begin{abstract}
Summary The relation between urinary albumin excretion rate (UAE), transcapillary escape rate of albumin $\left(\mathrm{TER}_{\mathrm{alb}}\right)$, haemostatic factors, ambulatory blood pressure, and metabolic variables was investigated in 45 Type II (non-insulin-dependent) diabetic patients without overt nephropathy or uncontrolled blood pressure. We enrolled 44 patients in a placebo controlled study to test the effects of 3 week long treatment with low-molecular weight heparin (tinzaparin) on the same variables. BMI, $24 \mathrm{~h}$ systolic and diastolic blood pressure, plasma concentrations of triglycerides, fasting glucose, factor VIII, von Willebrand factor (vWf), fibrinogen, $\alpha-2$ macroglobulin, and fibronectin were notably higher in patients with increased albuminuria compared with normoalbuminuric patients, whereas the $\mathrm{TER}_{\mathrm{alb}}$ was similar in the two groups. TER $\mathrm{Rlb}_{\mathrm{alb}}$ correlated with fasting plasma glucose. UAE correlated more closely than TER $\mathrm{Tlb}_{\mathrm{alb}}$ with $24 \mathrm{~h}$ ambulatory blood pressure, $\mathrm{vWf}$, and factor VIII. Urinary albumin excretion rate was unchanged during tinzaparin $[28.9 \pm 5.6$ vs $28.1 \pm 6.0 \mu \mathrm{g} / \mathrm{min}$ (geometric mean (antilog SD)] vs placebo $(18.0 \pm 5.4$ vs $17.6 \pm 5.3 \mu \mathrm{g} / \mathrm{min}$ ), and no change was found in TER $_{\text {alb }}[6.3 \pm 1.6$ vs $6.0 \pm 1.5 \% / h$ (means \pm SD), and
\end{abstract}

$6.3 \pm 1.5$ vs $5.6 \pm 1.8 \% / \mathrm{h}$; tinzaparin versus placebo, respectively]. Only minor changes were observed in blood pressure, lipids, glycaemic control and haemostatic factors. This study shows no correlation between albuminuria and transcapillary escape rate in Type II diabetic patients without overt nephropathy or uncontrolled blood pressure. UAE is related to markers of atherosclerosis, endothelial injury and dysfunction, and haemostatic factors. Moreover, UAE correlates much more than TER alb with $24 \mathrm{~h}$ ambulatory blood pressure, von Willebrand factor, and factor VIII. Finally, short-term treatment with tinzaparin does not change the transvascular or glomerular leakage of albumin. These results indicate that TER $_{\mathrm{alb}}$ is not a sensitive marker of microvascular dysfunction in such patients and that factors other than abnormal glycosaminoglycan metabolism may contribute to the vascular damage of these patients. [Diabetalogia (1999) 42: 60-67]

Keywords Transcapillary escape rate of albumin, microalbuminuria, albuminuria, low-molecular weight heparin, heparin.
Received: 2 February 1998 and in final revised form: 1 September 1998

Corresponding author: S. Nielsen, M. D., Medical Department M (Endocrinology \& Diabetes), Århus Kommunehospital, DK 8000, Århus C, Denmark

Abbreviations: UAE, Urinary albumin excretion rate; $\mathrm{TER}_{\mathrm{alb}}$, transcapillary escape rate of albumin; $\mathrm{IVM}_{\mathrm{alb}}$, intravascular mass of albumin; $\mathrm{J}_{\mathrm{alb}}$, outflux of albumin; HS, heparan sulfate; GAG, glycosaminoglycan; LMWH, low-molecular weight heparin; AMBP, ambulatory blood pressure; PV, plasma volume; $\mathrm{J}_{\mathrm{alb}}$, flow of albumin; vWf, von Willebrand factor; $\mathrm{U}_{\mathrm{alb} / \mathrm{cre}}$, albumin to creatinine ratio.
Type II (non-insulin-dependent) diabetic patients with abnormal urinary albumin excretion rate (UAE), even in the microalbuminuric range (UAE 20-200 $\mu \mathrm{g} / \mathrm{min}$ ), have an increased prevalence of vascular disease and risk of cardiovascular events compared with patients with normoalbuminuria (UAE $<20 \mu \mathrm{g} / \mathrm{min}$ ) [1-5]. The association has raised the hypothesis that patients with increased albuminuria do not only have glomerular disease but also extensive vascular damage $[6,7]$. Increased transcapillary escape rate of albumin $\left(\mathrm{TER}_{\mathrm{alb}}\right)$ [i.e. the fraction 
of intravascular mass of albumin $\left(\mathrm{IVM}_{\mathrm{alb}}\right)$ passing to the extravascular space per unit of time] has been found in Type II diabetic subjects; however, the precise relation with the degree of albuminuria remains unclear [7-9].

One underlying mechanism of increased $\mathrm{TER}_{\mathrm{alb}}$ is suggested to be an alteration in either the production or sulphation degree of heparan sulfate (HS), a glycosaminoglycan (GAG) sidechain of proteoglycans normally found in basement membranes and extracellular matrix. The presence of normally sulphated HS GAG is associated with a diminished permeability of negatively charged plasma proteins across the vascular wall bed due to charge repulsion and size exclusion [6, 10]. Moreover, HS GAG stimulates normal extracellular matrix protein synthesis, inhibits mesangial cell proliferation and possesses anticoagulative properties $[6,10-12]$. Treatment with HS like molecules such as unfractionated or low-molecular weight heparin (LMWH) [13], heparinoid [14], and an orally available GAG [15] has been shown to reduce albuminuria in diabetic patients with abnormal UAE.

This study was undertaken to evaluate the relation between UAE, TER $\mathrm{alb}_{\mathrm{ab}}$, haemostatic factors and metabolic variables in Type II diabetic patients without clinically overt nephropathy and uncontrolled blood pressure. Moreover, we examined the effect of shortterm treatment with a LMWH on these variables.

\section{Subjects and methods}

Subjects. We recruited 20 Type II diabetic patients with a urinary albumin to creatinine ratio $\left(\mathrm{U}_{\mathrm{alb} / \mathrm{cr}}\right)$ less then $2.0 \mathrm{mg} / \mathrm{mmol}$ and 25 Type II diabetic patients with a ratio of $2.0-25 \mathrm{mg} /$ mmol from the outpatient clinic. All patients were to have a serum creatinine less than $150 \mu \mathrm{mol} / \mathrm{l}$ and no proliferative retinopathy. This approach was used to obtain a wide range of normoand microalbuminuria as well as low-range macroalbuminuria without other evidence of overt clinical nephropathy. Other criteria of inclusion were: Caucasian, aged 40 to 70 years, age at diagnosis 30 years or older and diabetes duration longer than 1 year, blood pressure less than $160 / 90 \mathrm{mmHg}$ irrespective of ongoing treatment, $\mathrm{HbA}_{1 \mathrm{c}}$ less than $12 \%$, body mass index (BMI) less than $35 \mathrm{~kg} / \mathrm{m}^{2}$. Excluded from the study were patients with severe heart failure, unstable angina pectoris, untreated hypertension, known endocrine or renal disease unrelated to diabetes, known hepatic, haematological or malignant disease, as well as pregnant or lactating women and women of childbearing potential not using medical contraceptives. We also included patients with a spontaneous prothrombin time less than 0.80 (ref.: 0.80-1.20) or on ongoing anticoagulative therapy, or taking medication (other than antidiabetic or antihypertensive drugs) known to affect glucose homeostasis or blood pressure, as well as patients who had had a stroke or acute myocardial infarction within the past 6 months. Sodium intake was unrestricted and none of the patients was on a low protein diet. Antihypertensive medication was used by 22 patients, of these 14 used an ACE-inhibitor either alone $(n=11)$ or in combination with other agents $(n=3)$. The remaining 8 patients used diuretics, beta-blocking agents, and calcium an- tagonists either alone or as combination therapy. The study was approved by the local ethics committee and informed consent was obtained from all participating patients.

Methods. UAE was measured by radioimmunoassay [16] and calculated as the geometric mean of 3 consecutive 24 hour urine collections. Urinary sterility was checked using a dipstick method (Multistix 8 SG Ames, Bayer Denmark A/S, Frederiksberg, Denmark) followed by a urinary culture if infection could not be excluded.

TER $_{\mathrm{alb}}$ was assessed as described by Parving [17]. The patients were studied in the morning between 8 and 10 o'clock after an overnight fast. A catheter was inserted in an antecubital vein in each arm for tracer injection and blood sampling and the patients then rested for $1 \mathrm{~h}$ in the supine position. Hereafter a $10 \mathrm{ml}$ baseline blood sample was obtained without stasis and followed by a bolus injection (30 s) containing $0.2 \mathrm{MBq}$ ${ }^{125}$ I-albumin. The exact amount of tracer was assessed by weighing the syringes before and after injection. Additional $10 \mathrm{ml}$ blood samples were collected without stasis after 10,15, $20,30,40,50,55$, and $60 \mathrm{~min}$ to count plasma radioactivity and to measure the total plasma protein concentration in duplicate by refractometry (Bellingham and Stanley, Turnbridge Wells, UK). Radiotracer activity was corrected for the total plasma protein concentration and the slope of the linear regression of radioactivity on time was used to calculate TER $_{\mathrm{alb}}$ (i.e. the plasma tracer disappearance rate). Plasma volume (PV) was calculated using the intercept of the regression line extrapolated to time zero and the injected amount of radiotracer and corrected to $1.73 \mathrm{~m}^{2}$ body surface area. The IV$\mathrm{M}_{\mathrm{alb}}$ was derived by multiplying PV by the serum albumin concentration and the outflow of albumin $\left(\mathrm{J}_{\mathrm{alb}}\right)$ from multiplying IVM $_{\text {alb }}$ by TER alb $_{\text {. }}$

Twenty-four hour ambulatory blood pressure (AMBP) was measured using a portable blood pressure monitor (SpaceLabs model 90202, Redmond, Wash., USA) using oscillometry [18]. The device was programmed to measure blood pressure every 20 min between 06.00 and 24.00 hours and every hour during the night. Patients recorded actual time for going to bed and rising in the morning for correct assessment of day and night blood pressures.

$\mathrm{HbA}_{1 \mathrm{c}}$ was measured by HPLC and plasma glucose by a glucose oxidase technique. Plasma cholesterol was assessed by continuous-flow analysis, plasma triglycerides by an enzymatic technique, and plasma HDL-cholesterol by a dextran sulfate- $\mathrm{Mg}^{2+}$ precipitation procedure. Serum creatinine was measured by a modified Jaffe's reaction. Von Willebrand factor (vWf) was measured by ELISA, as reported previously [19]. Factor VIII was quantitated by ELISA [20], and plasma $\alpha-2$ macroglobulin, fibrinogen, and total fibronectin by nefelometry (BNA, Behring AG, Germany) using monospecific rabbit antibodies (Dakopatts, Roskilde, Denmark). Procoagulant factor VII function (F VII:C) was recorded by a one-stage coagulometric method employing Simplastin Excel (Organon Tekika, Turnhout, Belgium) as the tissue factor containing reagent. The prothrombin fragment $\mathrm{F} 1+2$ was quantitated by an ELISA method, Enzygnost F1 +2 micro (Behring, Marburg, Germany).

Protocol. The study was designed as a cross-sectional study followed by a double-blind, randomized, placebo controlled intervention trial.

Cross-sectional study. All patients completed three $24 \mathrm{~h}$ urine samples and a $24 \mathrm{~h}$ AMBP measurement, this was followed by assessment of TER $\mathrm{Tlb}_{\mathrm{alb}}$ and baseline blood samples for haemostatic and metabolic variables. 
Double-blind study. Following each TER $\mathrm{Tlb}_{\mathrm{ab}}$ measurement all but one patients were randomized in a double-blind, placebo controlled design for treatment with subcutaneous (thigh) injections of tinzaparin $50 \mathrm{IU} / \mathrm{kg}$ once daily (maximum 5000 IU) or with an equal amount of $0.9 \%$ saline. Block randomization was used. Thus, patients with a $\mathrm{U}_{\mathrm{alb} / \mathrm{cr}}$ below and above $2.0 \mathrm{mg} / \mathrm{mmol}$ were separated into two groups and randomized in blocks of 4 (2 tinzaparin, 2 placebo) in order to obtain equivalent numbers of patients with elevated albuminuria in the two treatment arms. The patients were asked to return the study medication vials and injection equipment (singleuse syringes and needles) for evaluation of compliance. At the end of the treatment $324 \mathrm{~h}$ urine collections were obtained and the patients returned for blood sampling, measurement of TER $_{\mathrm{alb}}$ and $24 \mathrm{~h} \mathrm{AMBP}$. We withdrew two placebo treated patients from the study during the treatment period: one patient was excluded due to unsatisfactory injection of the study drug. A second patient was excluded because of a non-fatal myocardial infarction after 19 days of placebo treatment. This event was unprovoked and was not found to be related to the subject's participation in the study. A total of 22 tinzaparin treated and 20 placebo treated patients completed the study. Among these patients the 3 weeks measurement of TER $\mathrm{alb}_{\mathrm{a}}$ was technically insufficient in one patient (placebo) and the urine collection was incomplete in another patient (placebo). The proportion of patients using antihypertensive medication, including ACE-inhibitors, was not different between the groups.

Statistics. Values are given as means \pm SD unless otherwise indicated except UAE which was $\log (10)$ transformed due to the positively skewed distribution and therefore given as the geometric mean $(\times / \div$ (i.e. multiplied/divided by) antilog SD). Statistical analyses at baseline were done using Student's $t$-test, the Mann-Whitney two sample test, Fisher's exact test or the $\chi^{2}$ test. For longitudinal data Student's $t$-test for paired data and Wilcoxon test for matched pairs were used for within group analysis. Two-way analysis of variance (ANOVA) for repeated measurements was used for between group comparisons. Multiple regression analysis was done by stepwise linear regression analysis. Correlations were evaluated by Pearson's $r$. To compare the strength of the relationships between risk factors and TER $_{\text {alb }}$ or UAE, Choi's approach [21] was used, which involves regression analysis of the ranked risk factor level(s) vs the

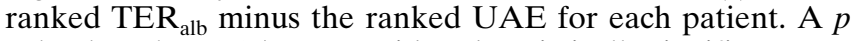
value less than 0.05 was considered statistically significant.

Power calculation. The probability of detecting a decline in UAE of (means \pm SD) $17 \pm 25 \%$ (values obtained from Myrup et al. [13]) using a paired $t$-test $(n=20)$ is $82 \%$. The probability of detecting a change in $\mathrm{TER}_{\mathrm{alb}}$ of $20 \%$ (SD 20\%) using a paired $t$-test is greater than $0.98(n=19)$ and greater than 0.80 $(n=10)$.

\section{Results}

Cross sectional study. A total of 45 patients [21 with normal UAE (range 1.9-19.9 $\mu \mathrm{g} / \mathrm{min}$ ) and 24 with increased UAE (range 31.3-1019 $\mu \mathrm{g} / \mathrm{min}$ )] were enrolled. They were $27 \mathrm{men}$ and 18 women, aged $58 \pm 8$ years, with BMI $27.9 \pm 4.1 \mathrm{~kg} / \mathrm{m}^{2}, \quad \mathrm{HbA}_{1 \mathrm{c}}$ $8.4 \pm 1.6 \%$, and serum creatinine $81(60-146) \mu \mathrm{mol} / \mathrm{l}$ [mean (range)]. Compared with normoalbuminuric patients these variables were higher in patients with
Table 1. Univariate correlations of UAE, TER $\mathrm{alb}_{\text {ib }}$ in Type II diabetic patients without overt nephropathy or uncontrolled blood pressure

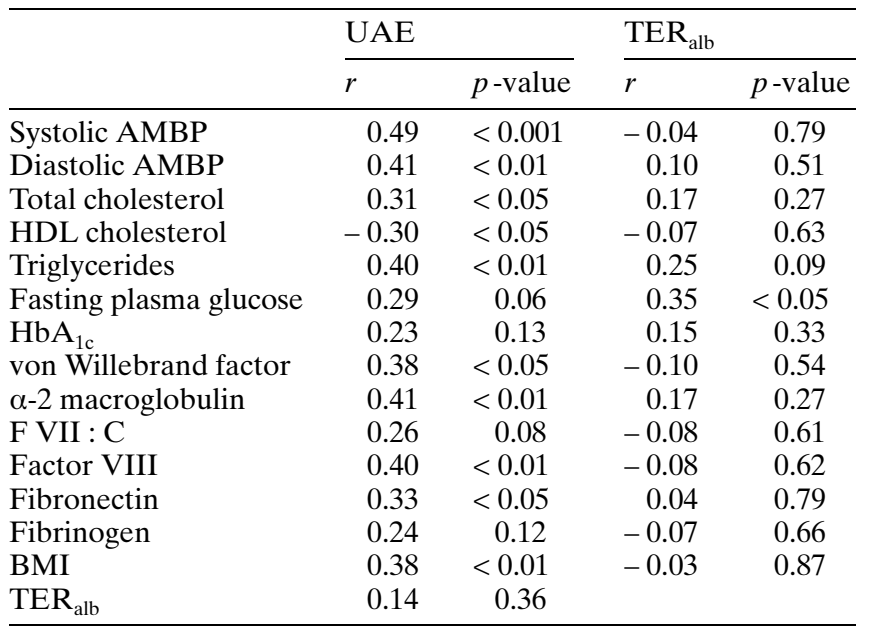

Table 2. Characteristics of patients randomized to treatment with tinzaparin or placebo

\begin{tabular}{lcc}
\hline & $\begin{array}{c}\text { Tinzaparin } \\
(n=22)\end{array}$ & $\begin{array}{c}\text { Placebo } \\
(n=22)\end{array}$ \\
\hline Age (years) & $58 \pm 7$ & $58 \pm 8$ \\
Sex (men/women) & $16 / 6$ & $9 / 11$ \\
Diabetes duration (years) & $10 \pm 9$ & $10 \pm 9$ \\
BMI (kg/m $\left.{ }^{2}\right)$ & $28.4 \pm 4.5$ & $27.2 \pm 3.8$ \\
HbA $1 \%$ ) & $8.6 \pm 1.8$ & $8.1 \pm 1.4$ \\
24 h AMBP (mm Hg) & $133 / 78 \pm 16 / 8$ & $133 / 76 \pm 17 / 7$ \\
Antihypertensive treatment (yes/no) & $15 / 7$ & $9 / 13$ \\
Antidiabetic treatment (d/o/i) & $4 / 11 / 7$ & $2 / 10 / 10$ \\
\hline
\end{tabular}

Values are means \pm SD

$\mathrm{d}=$ diet, $\mathrm{o}=$ oral hypoglycaemic agents, $\mathrm{i}=$ insulin

abnormal albuminuria: BMI $(26.6 \pm 4.0$ vs $29.5 \pm 3.8$ $\left.\mathrm{kg} / \mathrm{m}^{2}, p<0.02\right), 24 \mathrm{~h}$ systolic $(125 \pm 13$ vs $142 \pm$ $15 \mathrm{mmHg}, p<0.001)$ and diastolic $(74 \pm 7$ vs $81 \pm$ $8 \mathrm{mmHg}, p<0.005)$ AMBP, triglycerides ([median $\left(25^{\text {th }}-75^{\text {th }}\right.$ percentile] $1.41(0.89-2.06)$ vs 2.25 (1.49-2.94) mmol/l, $p<0.03$ ), fasting plasma glucose [8.3 (6.9-9.2) vs $9.9(7.8-12.5) \mathrm{mmol} / \mathrm{l}, p<0.04]$, factor VIII $(1.27 \pm 0.37$ vs $1.76 \pm 0.62 \mathrm{IU} / 1, p=0.002)$,

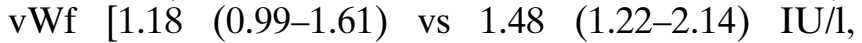
$p<0.02$ ], fibrinogen $4.9(4.4-5.7)$ vs $5.6(5.0-6.7) \mathrm{g} / \mathrm{l}$, $p<0.03), \alpha-2$ macroglobulin $(1.78 \pm 0.51$ vs $2.35 \pm$ $0.76 \mathrm{~g} / \mathrm{l}, p=0.005)$, and fibronectin $(0.44 \pm 0.09 \mathrm{vs}$ $0.51 \pm 0.11 \mathrm{~g} / \mathrm{l}, p=0.02$ ); normal vs abnormal albuminuria, respectively. TER $_{\text {alb }}$ was similar in the two groups $(6.2 \pm 1.8$ vs $6.6 \pm 1.3 \% / \mathrm{h})$. Likewise, no difference was found with respect to PV, IVM $\mathrm{Ilb}_{\mathrm{alb}}, \mathrm{J}_{\mathrm{alb}}$, total and HDL-cholesterol, or serum concentrations of creatinine and albumin, $\mathrm{HbA}_{1 \mathrm{c}}$, and age.

UAE correlated closely with $24 \mathrm{~h}$ systolic and diastolic AMBP, BMI, total cholesterol, HDL cholesterol, and triglyceride concentrations (Table 1). Moreover, correlations were found between UAE and vWf, factor VIII, $\alpha-2$ macroglobulin, and fibronectin. 
UAE and TER $\mathrm{Tlb}_{\mathrm{ab}}$ did not correlate very much and no important relation was observed between $\mathrm{TER}_{\mathrm{alb}}$ and AMBP, lipids or haemostatic measurements. TER $R_{\mathrm{alb}}$ correlated closely with fasting plasma glucose but not with $\mathrm{HbA}_{1 \mathrm{c}}$. There was no relation between night-time (resting) blood pressure and TER $\mathrm{alb}_{\text {. The }}$ pronounced correlations were consistent after controlling for $\mathrm{HbA}_{1 \mathrm{c}}$ and lipid concentrations in a multiple linear regression analysis (data not shown). When the data were subjected to Choi's analysis, we found that systolic AMBP $(p<0.01)$, vWf $(p<0.02)$, factor VIII $(p<0.04)$ were much better correlated with UAE than with TER $_{\text {alb }}$.

Double blind study. Table 2 shows the baseline characteristics of patients in the tinzaparin and placebo groups. Except for a slight, not significant majority of men in the tinzaparin group, the groups were well matched for age, UAE, glycaemic control, and blood pressure. UAE was comparable at baseline in the two groups and did not change much during treatment with tinzaparin [from $28.9 \times 1 \div 5.6$ to $28.1 \times 1$ $\div 6.0 \mu \mathrm{g} / \mathrm{min}$ (geometric mean $\times 1 \div$ antilog SD)] compared with placebo (from $18.0 \times 1 \div 5.4$ to $17.6 \times 1$ $\div 5.3 \mu \mathrm{g} / \mathrm{min}$ ) (Fig. 1). Moreover, baseline concentrations of TER $\mathrm{alb}_{\mathrm{ab}}, \mathrm{IVM}_{\mathrm{alb}}, \mathrm{J}_{\mathrm{alb}}$, and PV were similar (Table 3). Although PV and $\mathrm{IVM}_{\text {alb }}$ decreased in both groups, no change in $\mathrm{TER}_{\mathrm{alb}}$ was noted and the change in $\mathrm{J}_{\mathrm{alb}}$ found in the placebo group was not statistically different from the change observed in the tinzaparin group. Figure 2 shows the changes in TER $\mathrm{alb}_{\mathrm{al}}$ during treatment with tinzaparin and placebo. Dividing patients into tertiles of baseline UAE did not show any differences in treatment effects of tinzaparin versus placebo on UAE or $\mathrm{TER}_{\mathrm{alb}}$ (data not shown). Thus, the baseline concentration of UAE was not associated with different treatment responses. Furthermore, no change was observed in any of the haemostatic variables (Table 4). In both groups $24 \mathrm{~h}$ AMBP was unchanged and changed barely during treatment (Table 5). Finally, fasting plasma glucose and $\mathrm{HbA}_{1 \mathrm{c}}$ improved slightly during tinzaparin treatment but did not reach the level of statistical significance when compared with placebo. Total cholesterol increased significantly during tinzaparin com-
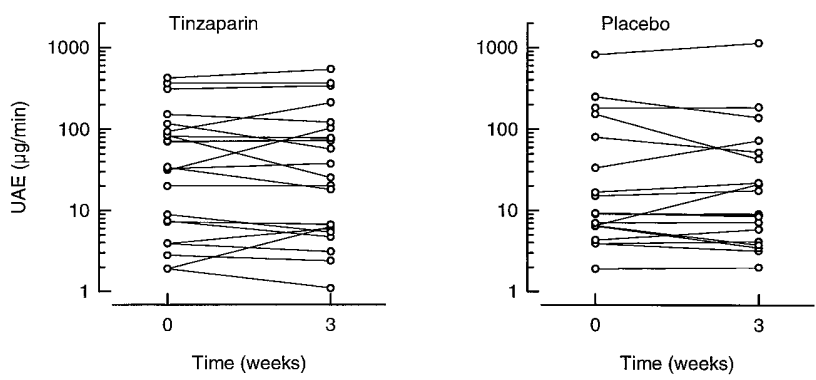

Fig. 1. Urinary albumin excretion rate in Type II diabetic patients with normal or controlled blood pressure before and after 3 weeks of treatment with tinzaparin (50 IU $/ \mathrm{kg}$ once daily) and placebo $(0.9 \%$ saline $)$
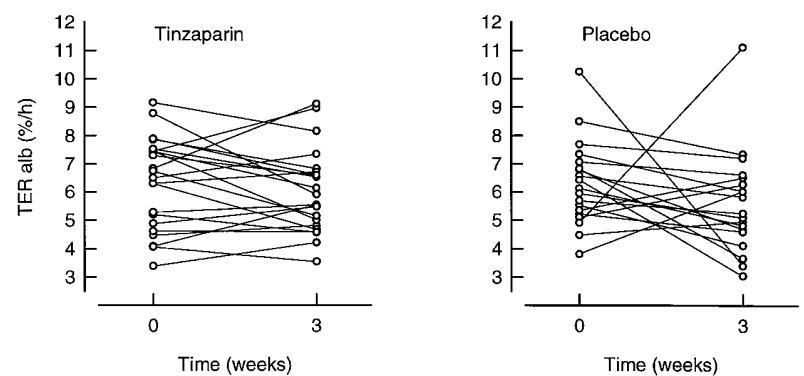

Fig. 2. Transcapillary escape rate of albumin in Type II diabetic patients with normal or controlled blood pressure before and after 3 weeks of treatment with tinzaparin (50 IU/kg once daily) and placebo ( $0.9 \%$ saline)

pared with placebo and minor fluctuations were observed in plasma triglycerides during tinzaparin treatment (Table 6). Uncomplicated moderate haematoma was reported by three patients at the injection site but otherwise no adverse events were reported. Patients' compliance of the self-administrated injection regime was excellent based on evaluation of the returned vials and injection equipment.

\section{Discussion}

We examined the relation between UAE, TER $\mathrm{alb}_{\mathrm{al}}$ and cardiovascular risk factors as well as the effect of short term treatment with the LMWH, tinzaparin on

Table 3. Intravascular mass and dynamics of intravascular albumin during tinzaparin and placebo treatment

\begin{tabular}{|c|c|c|c|c|}
\hline & \multicolumn{2}{|l|}{ Tinzaparin } & \multicolumn{2}{|l|}{ Placebo } \\
\hline & Baseline & 3 weeks & Baseline & 3 weeks \\
\hline $\operatorname{TER}_{\mathrm{alb}}(\% / \mathrm{h})$ & $6.3 \pm 1.6$ & $6.0 \pm 1.5$ & $6.3 \pm 1.5$ & $5.6 \pm 1.8$ \\
\hline Plasma volume $(\mathrm{ml})$ & $3082 \pm 602$ & $2867 \pm 576^{\mathrm{a}}$ & $2994 \pm 466$ & $2693 \pm 379^{c}$ \\
\hline Plasma volume $\left(\mathrm{ml} / 1.73 \mathrm{~m}^{2}\right)$ & $2713 \pm 342$ & $2515 \pm 295^{b}$ & $2815 \pm 323$ & $2533 \pm 260^{c}$ \\
\hline Serum albumin $(g / 1)$ & $41 \pm 2$ & $41 \pm 3$ & $41 \pm 3$ & $40 \pm 4$ \\
\hline $\operatorname{IVM}_{\text {alb }}\left(\mathrm{g} / 1.73 \mathrm{~m}^{2}\right)$ & $112 \pm 14$ & $103 \pm 15^{\mathrm{b}}$ & $115 \pm 14$ & $99 \pm 21$ \\
\hline $\mathrm{J}_{\mathrm{alb}}\left(\mathrm{g} / \mathrm{h} \cdot 1.73 \mathrm{~m}^{2}\right)$ & $709 \pm 200$ & $614 \pm 168^{b}$ & $718 \pm 167$ & $572 \pm 188^{a}$ \\
\hline
\end{tabular}

Values are means \pm SD

${ }^{\mathrm{a}} p<0.05,{ }^{\mathrm{b}} p<0.01,{ }^{\mathrm{c}} p<0.001$ compared with baseline 
Table 4. Haemostatic factors during tinzaparin and placebo treatment

\begin{tabular}{|c|c|c|c|c|}
\hline & \multicolumn{2}{|l|}{ Tinzaparin } & \multicolumn{2}{|l|}{ Placebo } \\
\hline & Baseline & 3 weeks & Baseline & 3 weeks \\
\hline$\alpha$-macroglobulin $(\mathrm{g} / \mathrm{l})$ & $2.00 \pm 0.74$ & $2.11 \pm 0.74$ & $2.11 \pm 0.67$ & $2.12 \pm 0.61$ \\
\hline F VII : C (IU/l) & $1.39 \pm 0.26$ & $1.46 \pm 0.29$ & $1.41 \pm 0.33$ & $1.47 \pm 0.29$ \\
\hline Factor VIII (IU/l) & $1.62(1.11-1.97)$ & $1.71(1.45-2.46)^{\mathrm{ab}}$ & $1.31(1.14-1.50)$ & $1.33(1.21-1.71)$ \\
\hline Prothrombin fragment $1+2(\mathrm{nmol} / \mathrm{l})$ & $1.44(0.95-1.80)$ & $1.58(1.02-2.05)$ & $1.63(1.32-1.85)$ & $1.61(1.32-1.80)$ \\
\hline Fibrinogen $(\mathrm{g} / \mathrm{l})$ & $5.6(5.1-6.0)$ & $5.2(4.8-6.2)$ & $4.9(4.3-6.1)$ & $5.2(4.6-5.9)$ \\
\hline Fibronectin $(\mathrm{g} / \mathrm{l})$ & $0.50(0.38-0.55)$ & $0.53(0.47-0.75)^{\mathrm{c}}$ & $0.44(0.40-0.48)$ & $0.47(0.42-0.52)$ \\
\hline von Willebrand factor (IU/l) & $1.43(1.05-2.07)$ & $1.54(1.25-2.18)$ & $1.23(1.03-1.51)$ & $1.25(1.05-1.66)$ \\
\hline
\end{tabular}

Values are means $\pm \mathrm{SD}$; median $\left(25^{\text {th }}-75^{\text {th }}\right.$ percentile $)$

${ }^{\mathrm{a}} p<0.01$ compared with baseline; ${ }^{\mathrm{b}} p<0.05,{ }^{\mathrm{c}} 0.05<p<0.10$ change from baseline compared with placebo

Table 5. Twenty-four hour ambulatory blood pressure during tinzaparin and placebo treatment

\begin{tabular}{|c|c|c|c|c|}
\hline & \multicolumn{2}{|c|}{ Tinzaparin } & \multicolumn{2}{|l|}{ Placebo } \\
\hline & Baseline & 3 weeks & Baseline & 3 weeks \\
\hline Systolic daytime $(\mathrm{mm} \mathrm{Hg})$ & $136 \pm 16$ & $135 \pm 17$ & $136 \pm 18$ & $138 \pm 16$ \\
\hline Systolic nighttime ( $\mathrm{mm} \mathrm{Hg}$ ) & $124 \pm 18$ & $123 \pm 20$ & $124 \pm 19$ & $126 \pm 20$ \\
\hline Systolic diurnal $(\mathrm{mm} \mathrm{Hg})$ & $133 \pm 16$ & $132 \pm 17$ & $133 \pm 17$ & $134 \pm 17$ \\
\hline Diastolic daytime (mm Hg) & $81 \pm 9$ & $79 \pm 10$ & $80 \pm 7$ & $80 \pm 6$ \\
\hline Diastolic nighttime ( $\mathrm{mm} \mathrm{Hg}$ ) & $69 \pm 10$ & $67 \pm 11$ & $68 \pm 10$ & $69 \pm 10$ \\
\hline Diastolic diurnal ( $\mathrm{mm} \mathrm{Hg}$ ) & $78 \pm 8$ & $75 \pm 9^{\mathrm{a}}$ & $76 \pm 7$ & $77 \pm 7$ \\
\hline
\end{tabular}

Values are means \pm SD

${ }^{\mathrm{a}} p<0.05$ compared with baseline

Table 6. Metabolic parameters and BMI during tinzaparin and placebo treatment

\begin{tabular}{|c|c|c|c|c|}
\hline & \multicolumn{2}{|l|}{ Tinzaparin } & \multicolumn{2}{|l|}{ Placebo } \\
\hline & Baseline & 3 weeks & Baseline & 3 weeks \\
\hline Total cholesterol (mmol/1) & $5.4 \pm 1.0$ & $6.1 \pm 1.4^{\mathrm{bc}}$ & $5.8 \pm 1.2$ & $5.8 \pm 1.0$ \\
\hline HDL cholesterol (mmol/l) & $1.1(0.9-1.2)$ & $1.0(0.9-1.4)$ & $1.3(1.0-1.5)$ & $1.1(0.9-1.5)$ \\
\hline Triglycerides $(\mathrm{mmol} / \mathrm{l})$ & $1.96(1.02-2.69)$ & $1.82(1.23-3.91)^{\mathrm{a}}$ & $1.56(1.05-2.10)$ & $1.61(1.16-2.93)$ \\
\hline Fasting plasma glucose $(\mathrm{mmol} / \mathrm{l})$ & $10.2 \pm 3.0$ & $9.3 \pm 2.9^{\mathrm{a}}$ & $8.6 \pm 1.9$ & $9.2 \pm 2.0$ \\
\hline $\mathrm{HbA}_{1 \mathrm{c}}(\%)$ & $8.6 \pm 1.8$ & $8.3 \pm 1.6^{\mathrm{a}}$ & $8.1 \pm 1.5$ & $8.2 \pm 1.4$ \\
\hline Serum creatinine $(\mu \mathrm{mol} / \mathrm{l})$ & $78(67-95)$ & $75(64-100)$ & $77(71-82)$ & $74(70-83)$ \\
\hline $\mathrm{BMI}\left(\mathrm{kg} / \mathrm{m}^{2}\right)$ & $28.4 \pm 4.5$ & $28.6 \pm 4.6^{\mathrm{a}}$ & $27.2 \pm 3.7$ & $27.3 \pm 3.6$ \\
\hline
\end{tabular}

Values are means \pm SD; median $\left(25^{\text {th }}-75^{\text {th }}\right.$ percentile $)$

${ }^{\mathrm{a}} p<0.05,{ }^{\mathrm{b}} p<0.01$ compared with baseline, ${ }^{\mathrm{c}} p<0.05$ change from baseline compared with placebo

these variables in Type II diabetic patients with normal or low grade abnormal albuminuria and normal or controlled blood pressure. The results showed that $24 \mathrm{~h}$ AMBP, lipids, BMI, homeostatic factors and markers of endothelial injury are higher in patients with abnormal UAE compared with normal UAE. Moreover, $24 \mathrm{~h}$ systolic AMBP, vWf, and factor VIII were more closely correlated with UAE than with TER $\mathrm{Rlb}_{\mathrm{alb}}$. The TER $\mathrm{Tlb}_{\mathrm{alb}}$ was similar in patients with normal and raised UAE. Moreover, we found that treatment with tinzaparin for 3 weeks had no effect on UAE or TER ${ }_{\mathrm{alb}}$ and only minor effects on cardiovascular risk factors.

Our finding of a relation between UAE and many cardiovascular risk factors confirms that raised UAE is a cardiovascular risk marker in Type II diabetes. Previous studies have reported a similar increase of
TER $_{\text {alb }}$ in Type II diabetic patients with normoalbuminuria and overt proteinuria $[7,8]$. In another study $\mathrm{TER}_{\mathrm{alb}}$ was found to be increased in microalbuminuric but not normoalbuminuric patients [9]. Higher fasting plasma glucose concentration in the microalbuminuric patients, however, may have confounded the relation between TER $_{\mathrm{alb}}$ and UAE since both variables increase during hyperglycaemia [22-26]. In our study of patients with normal or low grade abnormal albuminuria we found no association between UAE and TER $\mathrm{alb}_{\mathrm{al}}$. We did not include patients with uncontrolled blood pressure because hypertension enhances UAE and TER $\mathrm{alb}_{\mathrm{alb}}[17,22,27-29]$. TER $\mathrm{alb}$ is normal in moderate hypertension $[22,30]$ and coexistence of microalbuminuria does not increase TER $\mathrm{Tlb}_{\mathrm{alb}}$ compared with microalbuminuria alone [30]. On the other hand microalbuminuria is associated with in- 
creased $\mathrm{TER}_{\mathrm{alb}}$ in non-diabetic subjects and normotensive, long-term Type I (insulin-dependent) diabetic patients [30-32]. Moreover, we excluded patients with proliferative retinopathy to minimize the risk of retinal bleeding during LMWH treatment. Absence of retinopathy indicates a higher proportion of nondiabetic renal disease in Type II diabetic patients with abnormal albuminuria; however, the exact proportion is being debated [33-35]. None of our patients had been diagnosed with non-diabetic renal disease and none had had a kidney biopsy. In theory, the absence of a correlation between UAE and TERalb could be due to a high proportion of patients using ACE-inhibitors since these drugs may have renal effects independent of their effects on systemic blood pressure [36]. Exclusion of this potential confounder did not improve the relation between UAE and TER $_{\mathrm{alb}}$ nor did it improve the correlations between $\mathrm{UAE}$ and other risk factors.

We found higher concentrations of Factor VIII, vWF, fibrinogen, $\alpha-2$ macroglobulin, and fibronectin in patients with raised UAE. Plasma concentrations of fibronectin and $\mathrm{vWf}$ are considered markers of endothelial injury and associated with glomerular disease in diabetes [37-40]. $\alpha-2$ macroglobulin is increased in patients with diabetic complications [41, 42]. Moreover, fibrinogen, vWf, F VII:C, and factor VIII (a liver synthesized protein bound to $\mathrm{vWf}$ in the circulation) are associated with a higher incidence of ischaemic heart disease. The finding of higher vWf and fibrinogen in patients with abnormal UAE confirms earlier results [40, 43]. Increased concentrations of haemostatic factors along with endothelial injury in Type II diabetic patients with abnormal UAE possibly contributes to the increased cardiovascular risk in these patients. None of the haemostatic factors were related to $\mathrm{TER}_{\mathrm{alb}}$. In conclusion, $\mathrm{TER}_{\mathrm{alb}}$, as opposed to UAE, is not a sensitive marker of the degree of microvascular/endothelial dysfunction in microalbuminuric or low grade proteinuric Type II diabetic subjects with normal or controlled blood pressure.

It has been hypothesized that early phases of increased albuminuria in diabetes could represent a renal manifestation of generalized vascular damage [6, 7]. The pathogenic mechanism was first formulated in Type I diabetes [6] and involves a genetically based abnormal metabolism of HS proteoglycan of extracellular matrix and basement membranes with a decrease of normally sulphated, negatively charged HS GAG sidechains. These changes provide the biochemical basis for increased transvascular permeability of negatively charged plasma proteins which promotes extravascular coagulation and structural damage of the vasculature and glomeruli $[6,10-12,44]$. Animal [45-47] and human studies [13-15] suggest that treatment with heparin and orally available GAGs improve GAG metabolism, prevent renal morphological changes, and prevent progression of albuminuria. Thus, treatment with LMWH, danaparoid sodium, and sulodexide reduced microalbuminuria in Type I $[13,14]$ and Type II $[15]$ diabetic patients with abnormal albuminuria. In the latter study [15], a decrease in blood pressure and glycaemic control was also observed during sulodexide treatment which may have confounded the ability to find a positive effect. We found no effect on UAE or TER $\mathrm{alb}_{\mathrm{al}}$ during 3 weeks treatment with tinzaparin in Type II diabetic patients with varying degrees of albuminuria. This does, however, not exclude a long-term treatment effect. The lack of effect on $\mathrm{TER}_{\mathrm{alb}}$ or UAE could be due to a type 2 error. The probability of detecting a change of $20 \pm 20 \%$ (paired $t$-test) is greater than $0.80(n=10)$. Moreover, tinzaparin was given in conventional anticoagulative doses which may be different from doses required to affect extracellular matrix metabolism. Different formulas of low-molecular weight and unfractionated heparins may differ in chemical composition, especially in their sulphation ratio, which could have an important effect on GAG metabolism. Plasma volume decreased similarly in both groups. Plasma albumin concentrations were unchanged and, consequently, lower IVM ${ }_{\text {alb }}$ was found after treatment. Thus, the total outflow of albumin $\left(\mathrm{J}_{\mathrm{alb}}\right)$ decreased in both groups. The reason for these findings is not clear. There was no difference between the groups and the fraction of the $\mathrm{IVM}_{\mathrm{alb}}$ disappearing from the circulation (i.e. $\mathrm{TER}_{\mathrm{alb}}$ ) was similar and unchanged in the two groups. The lack of effect of tinzaparin treatment as well as the lack of an association between UAE and TER ${ }_{\mathrm{alb}}$ indicate that abnormal GAG metabolism either might not be uniformly present or might not be a cause of the widespread vascular disease of Type II diabetic patients with abnormal albuminuria. Whether quantitative differences caused by other cardiovascular risk factors such as hyperglycaemia or hypertension or both on UAE and TER $\mathrm{alb}_{\mathrm{ab}}$ exist in Type II diabetes remains to be defined.

Heparin treatment could lower blood pressure by decreasing blood viscosity [48] and stimulates endothelial lipoprotein lipase activity which possibly decreases plasma triglycerides. The lack of effect of tinzaparin on TER $\mathrm{Tlb}_{\mathrm{a}}$ and UAE cannot be explained by changes in blood pressure or glycaemic control. Tinzaparin treatment was associated with a slight decrease in $24 \mathrm{~h}$ diastolic AMBP. Glycaemic control improved slightly during tinzaparin. Therefore, if anything, the reduction in blood pressure and plasma glucose would have tended to decrease TER $_{\mathrm{alb}}$ and UAE. Only minor changes were observed in haemostatic factors and plasma lipids during treatment with tinzaparin, although a slight increase in total cholesterol was noted.

In conclusion our study shows no association between TER $_{\mathrm{alb}}$ and UAE in microalbuminuric or low 
grade proteinuric Type II diabetic subjects with normal or controlled blood pressure. This was also true after exclusion of patients using ACE-inhibitors. The degree of albuminuria, but not TER $\mathrm{alb}_{\text {, }}$, is a sensitive marker of microvascular dysfunction and correlates more closely than TER alb with systolic blood pressure, vWf, and factor VIII. Moreover, our results do not show that short-term treatment with tinzaparin exerts a potentially beneficial effect on glomerular and vascular leakage of albumin in Type II diabetic subjects. Our findings indicate that factors other than abnormal GAG metabolism contribute to the vascular damage in these patients.

Acknowledgements. We wish to thank E. Horneman, M. Møller, and $\mathrm{H}$. Pedersen as well as the staff of the Coagulation Laboratory for excellent technical assistance. This study was supported by Novo Nordisk Farmaka Danmark and by The Danish Diabetes Association.

\section{References}

1. Neil A, Hawkins M, Potok M, Thorogood M, Cohen D, Mann J (1993) A prospective population-based study of microalbuminuria as a predictor of mortality in NIDDM. Diabetes Care 16: 996-1003

2. Schmitz A, Vaeth M (1988) Microalbuminuria: a major risk factor in non-insulin-dependent diabetes. A 10-year followup study of 503 patients. Diabet Med 5: 126-134

3. Mattock MB, Morrish NJ, Viberti G, Keen H, Fitzgerald AP, Jackson G (1992) Prospective study of microalbuminuria as predictor of mortality in NIDDM. Diabetes 41: 736-741

4. Jarrett RJ, Viberti GC, Argyropoulos A, Hill RD, Mahmud U, Murrells TJ (1984) Microalbuminuria predicts mortality in non-insulin-dependent diabetics. Diabet Med 1: $17-19$

5. Mogensen CE (1984) Microalbuminuria predicts clinical proteinuria and early mortality in maturity-onset diabetes. N Engl J Med 310: 356-360

6. Deckert T, Feldt-Rasmussen B, Borch-Johnsen K, Jensen T, Kofoed-Enevoldsen A (1989) Albuminuria reflects widespread vascular damage. The Steno hypothesis. Diabetologia 32: 219-226

7. Parving HH, Nielsen FS, Bang LE et al. (1996) Macro-microangiopathy and endothelial dysfunction in NIDDM patients with and without diabetic nephropathy. Diabetologia 39: $1590-1597$

8. Nielsen FS, Rossing P, Gall MA et al. (1997) Lisinopril improves endothelial dysfunction in hypertensive NIDDM subjects with diabetic nephropathy. Scand J Clin Lab Invest 57: 427-434

9. Nannipieri M, Rizzo L, Rapuano A, Pilo A, Penno G, Navalesi $R$ (1995) Increased transcapillary escape rate of albumin in Type II diabetic patients. Diabetes Care 18: 1-9

10. Gambaro G, Baggio B (1996) Glycosaminoglycans: a new paradigm in prevention of proteinuria and progression of glomerular disease. Nephrol Dial Transplant 11: 762-764

11. Groggel GC, Hughes ML (1995) Heparan sulfate stimulates extracellular matrix protein synthesis by mesangial cells in culture. Nephron 71: 197-202

12. Rosenberg RD, Shworak NW, Liu J, Schwartz JJ, Zhang L (1997) Heparan sulfate proteoglycans of the cardiovascular system. Specific structures emerge but how is synthesis regulated? J Clin Invest 99: 2062-2070

13. Myrup B, Hansen PM, Jensen T et al. (1995) Effect of lowdose heparin on urinary albumin excretion in insulin-dependent diabetes mellitus. Lancet 345: 421-422

14. van der Pijl JW, van der Woude FJ, Geelhoed-Duijvenstijn PHLM et al. (1997) Danaparoid sodium lowers proteinuria in diabetic nephropathy. J Am Soc Nephrol 8: 456-462

15. Solini A, Vergnani L, Ricci F, Crepaldi G (1997) Glycosaminoglycans delay the progression of nephropathy in NIDDM. Diabetes Care 20: 819-823

16. Christensen CK, Ørskov C (1984) Rapid screening PEG immunoassay for quantification of pathological microalbuminuria. Diabetic Nephrol 3: 92-94

17. Parving HH, Gyntelberg F (1973) Transcapillary escape rate of albumin and plasma volume in essential hypertension. Circ Res 32: 643-651

18. DeFronzo RA (1992) Insulin resistance, hyperinsulinemia, and coronary artery disease: a complex metabolic web. J Cardiovasc Pharmacol 20 [Suppl 11]:S1-S16

19. Ingerslev J (1987) A sensitive ELISA for von Willebrand factor (vWf:Ag). Scand J Clin Lab Invest 47: 143-149

20. Ingerslev J, Stenbjerg S (1986) Enzyme linked immunosorbent assay (ELISA) for the measurement of factor VIII coagulant antigen (CAg) using haemophilic antibodies. Br J Haemat 62: 325-332

21. Choi SC (1977) Tests of equality of dependent correlation coefficients. Biometrika 64: 645-647

22. O'Hare JA, Ferriss JB, Twomey B, O'Sullivan DJO (1983) Poor metabolic control, hypertension and microangiopathy independently increase the transcapillary escape rate of albumin in diabetes. Diabetologia 25: 260-263

23. Parving HH (1976) Increased microvascular permeability to plasma proteins in short- and long-term juvenile diabetics. Diabetes 25: 884-889

24. Parving HH, Noer I, Deckert T et al. (1976) The effect of metabolic regulation on microvascular permeability to small and large molecules in short-term juvenile diabetics. Diabetologia 12: 161-166

25. Schmitz A, Hansen HH, Christensen T (1989) Kidney function in newly diagnosed Type II (non-insulin-dependent) diabetic patients, before and during treatment. Diabetologia 32: 434-439

26. Vora JP, Dolben J, Williams JD, Peters JR, Owens DR (1993) Impact of initial treatment on renal function in newly-diagnosed Type II (non-insulin-dependent) diabetes mellitus. Diabetologia 36: 734-740

27. Nielsen S, Schmitz A, Poulsen PL, Hansen KW, Mogensen CE (1995) Albuminuria and 24-h ambulatory blood pressure in normoalbuminuric and microalbuminuric NIDDM patients - A longitudinal study. Diabetes Care 18: 1434-1441

28. Parving HH, Mogensen CE, Jensen HA, Evrin PE (1974) Increased urinary albumin-excretion rate in benign essential hypertension. Lancet 1: 1190-1192

29. Parving HH, Kastrup J, Smidt UM (1985) Reduced transcapillary escape rate of albumin during acute blood pressure-lowering in Type I (insulin-dependent)diabetic patients with nephropathy. Diabetologia 28: 797-801

30. Nørgaard K, Jensen T, Feldt-Rasmussen B (1993) Transcapillary escape rate of albumin in hypertensive patients with Type 1 (insulin-dependent) diabetes mellitus. Diabetologia 36: 57-61

31. Jensen JS, Borch-Johnsen K, Jensen G, Feldt-Rasmussen B (1995) Microalbuminuria reflects a generalized transvascular albumin leakiness in clinically healthy subjects. Clin Sci 88: 629-633 
32. Feldt-Rasmussen B (1986) Increased transcapillary escape rate of albumin in Type I (insulin-dependent) diabetic patients with microalbuminuria. Diabetologia 29: 282-286

33. Parving HH, Gall M-A, Skott P et al. (1992) Prevalence and causes of albuminuria in non-insulin-dependent diabetic patients. Kidney Int 41: 758-762

34. Fioretto P, Mauer M, Brocco E et al. (1996) Patterns of renal injury in NIDDM patients with microalbuminuria. Diabetologia 39: 1569-1576

35. Olsen S, Mogensen CE (1996) How often is NIDDM complicated with non-diabetic renal disease? An analysis of renal biopsies and the literature. Diabetologia 39: $1638-1645$

36. Kasiske BL, Kalil RS, Ma JZ, Liao M, Keane WF (1993) Effect of antihypertensive therapy on the kidney in patients with diabetes: a meta-regression analysis. Ann Intern Med 118: 129-138

37. Ozata M, Kurt I, Azal O et al. (1995) Can we use plasma fibronectin levels as a marker for early diabetic nephropathy. Endocr J 42: 301-305

38. Stehouwer CD (1996) von Willebrand factor, dysfunction of the vascular endothelium, and the development of renal and vascular complications in diabetes. In: Mogensen CE (ed) The kidney and hypertension in diabetes mellitus. Kluwer Academic Publishers, Boston, Dordrecht, London, pp 155-163

39. Stehouwer CD, Nauta JJ, Zeldenrust GC, Hackeng WH, Donker AJ, den Ottolander GJ (1992) Urinary albumin excretion, cardiovascular disease, and endothelial dysfunction in non-insulin-dependent diabetes mellitus. Lancet 340: 319-323
40. Bruno G, Cavallo Perin P, Bargero G, Borra M, D'Errico N, Pagano G (1996) Association of fibrinogen with glycemic control and albumin excretion rate in patients with non-insulin-dependent diabetes mellitus. Ann Intern Med 125: 653-657

41. Brownlee M (1976) alpha1-Macroglobulin and reduced basement-membrane degradation in diabetes. Lancet 1: 779-780

42. Christe M, Gattlen P, Fritschi J et al. (1984) The contact phase of blood coagulation in diabetes mellitus and in patients with vasculopathy. Thrombosis Haemostasis 52: 221-223

43. Schmitz A, Ingerslev J (1990) Haemostatic measures in Type II diabetic patients with microalbuminuria. Diabet Med 7: 521-525

44. Dvorak HN, Senger DR, Dvorak AM, Harvey VS, McDonagh J (1985) Regulation of extravascular coagulation by microvascular permeability. Science 227: 1059-1061

45. Gambaro G, Cavazzana AO, Luzi P et al. (1992) Glycosaminoglycans prevent morphological renal alterations and albuminuria in diabetic rats. Kidney Int 42: 285-291

46. Gambaro G, Venturini AP, Noonan DM et al. (1994) Treatment with a glycosaminoglycan formulation ameliorates experimental diabetic nephropathy. Kidney Int 46: 797-806

47. Marshall SM, Hansen KW, Østerby R, Frystyk J, Ørskov H, Flyvbjerg A (1996) Effects of heparin on renal morphology and albuminuria in experimental diabetes. Am J Physiol 271:E326-E332

48. Mandal AK, Lyden TW, Saklayen MG (1995) Heparin lowers blood pressure: Biological and clinical perspectives. Kidney Int 47: 1017-1022 